\title{
Association of Clinicopathological features of Cholecystitis with Helicobacter Pylori Infection in Gall Bladders
}

\author{
Saleha Anjum Khan ${ }^{1}$, Huma Mushtaq ${ }^{2}$, Ahmad Raza ${ }^{3}$, Mohammad Nauman Mustafa4, Saeed Alam ${ }^{5}$ \\ ${ }^{1}$ Assistant Professor, Department of Surgery, Akbar Niazi Teaching Hospital, Islamabad \\ ${ }^{2}$ Associate Professor of Histopathology, Department of Pathology, Akbar Niazi Teaching Hospital, Islamabad \\ ${ }^{3}$ Associate Professor, Department of Surgery, Akbar Niazi Teaching Hospital, Islamabad \\ ${ }^{4}$ Professor, Department of Surgery, Frontier Medical and Dental College, Abbottabad \\ 5 Professor of Histopathology, Department of Pathology, Akbar Niazi Teaching Hospital Islamabad
}

\begin{abstract}
A BST RACT
Background: Helicobacter pylori (H. pylori) have been associated with gastritis, but its presence in other parts of the gastrointestinal system has not been studied much. Few previous studies have identified "H. pylori" in gallbladder and found its association in causing cholecystitis and gallstones, but there is limited data showing a significant association in Pakistan. This study was designed to identify $\mathrm{H}$. pylori microorganism in cholecystitis patients and find its association with the morphological changes seen in the affected gall bladders.

Material and Methods: All patients with acute and chronic cholecystitis admitted in Akbar Niazi Teaching Hospital (ANTH) between the ages of 18 and 80 years from January 2017 till March 2019, who underwent cholecystectomy, were included in the study. Gall bladder specimens were sent to Pathology department, ANTH after surgery and were analyzed for the presence of $\mathrm{H}$ pylori bacteria using Hematoxylin and Eosin and Giemsa staining. Signs of inflammation, hyperplasia, metaplasia, mucosal atrophy or erosion, lymphoid infiltration, fibrosis, cholesterolosis or any other morphological changes were also noted. Association of $\mathrm{H}$. pylori with cholecystitis and other morphological changes were assessed by Chi Square analysis. P value less than 0.05 was considered statistically significant.

Results: Chronic cholecystitis was present in $91 \%$ cases and acute cholecystitis in $9 \%$. Other histological findings were Hyperplasia $(10 \%)$, Metaplasia $(15 \%)$, Fibrosis $(79 \%)$, Cholesterolosis $(19 \%)$ and ulcerations $(36 \%)$. H pylori was found in $17 \%$ of gall bladders and all the cases were of chronic cholecystitis, with $11.7 \%$ males and $88 \%$ females. Gallstones were present in $76.4 \%$ cases and were more common in 41-60 years' age group (64.7\%). Other histological findings seen in $\mathrm{H}$. pylori positive cases were; Hyperplasia in $11.7 \%$ cases, Metaplasia in $17.6 \%$, Fibrosis in $94.1 \%$, cholesterolosis in $23.5 \%$ and ulcerations in $17.6 \%$ cases. Association of $\mathrm{H}$. pylori with gender, cholecystitis, gall stones, histological features and age distribution was non-significant.

Conclusion: Although $\mathrm{H}$. pylori infection has been found in cases of chronic cholecystitis and gall stone formation, its association with cholecystitis and other morphological changes could not be proved. Hence, it is uncertain whether $\mathrm{H}$. pylori eradication in patients with gastritis can prevent cholecystitis or gall stones formation.
\end{abstract}

Key words: Cholesterolosis, cholecystitis, gall stones, H. pylori

Authors' Contribution: Correspondence:

${ }^{1}$ Conception, synthesis, planning of Huma Mushtaq

Article info:

research. ${ }^{2}$ Data analysis, manuscript writing Email: huma.mushtaq@imdcollege.edu.pk

Received: April 20, 2019

Interpretation, and discussion, ${ }^{3-5}$ Active

participations in data collection

Cite this article. Khan SA, Mushtaq H, Razza A, Mustafa MN, Alam S. Association of

Clinicopathological features of Cholecystitis with Helicobacter Pylori Infection in Gall Bladders.

J Islamabad Med Dental Coll.2019; 8(3):117-122. doi: 10.35787/jimdc.v8i3.403

\section{Introduction}

Gallstone disease is the most commonly occurring disease in surgical practice with a prevalence of $10-15 \%$ in European population and $3-5 \%$ in Asian and African population. ${ }^{1}$ Internationally the reported prevalence of gallstone disease was $9.2 \%$ for Italy, $9.7 \%$ for Spain, 
28.5\% for Chile and $3.1 \%$ for Thailand. ${ }^{2}$ In Pakistan, the incidence reported in previous years was $9.03 \% .2,3$

All over the world surgical units are managing many patients with gallstones every year and with cholecystectomy as one of the most common elective surgical procedure. ${ }^{1}$ In our setup in ANTH Bara Kahu, since last one-year (2017-2018), number of surgeries performed for gallstones have been at the top of the list i.e. $22 \%$ of all general surgical procedures $(62 / 286)$. Hyperlipidemia, sedentary lifestyle, low fiber, high fat diet, metabolic syndrome and diabetes are the commonest causative factors of gallstone formation leading to cholecystitis. $^{4}$

In recent years, few studies from Middle East ${ }^{5}$ and Asia (China, ${ }^{4,6,7}$, Iran, 8,9, India ${ }^{10,11}$ ) have identified a new causative agent "H pylori" which plays a role in gall stone formation leading to cholecystitis. The initial study dates back to 1996 by Kawaguchi et al. ${ }^{12}$ who incidentally discovered a microorganism resembling $\mathrm{H}$ pylori from a cholecystectomy specimen. Since then many researches have been performed, but still this association has not been widely accepted due to the lack of proper evidence. Despite an overall percentage of approximately 20\% being detected in gallbladder mucosa, according to various studies ${ }^{4}$, its eradication has not been practiced or proposed for cholecystitis.

The prevalence of this bacteria is more in Asian population but only a few studies have been performed in Pakistan that have shown a significant association. ${ }^{3}$ Therefore further studies are required, to elucidate the role of Helicobacter in hepatobiliary diseases in our setup.

This gram-negative rod has previously been associated with gastritis and acid peptic disease ${ }^{8}$ for decades and studies have been carried out to show its association with gallstones, cholecystitis ${ }^{13,14}$ and gall bladder cancer. ${ }^{15}$ Many serological and histological methods ${ }^{16,17}$ have been used to detect its presence in gall bladder mucosa and bile including Giemsa staining, H\&E, PCR, Urease test, Warthin-starry ${ }^{18}$ test etc. Out of these Giemsa and H\&E are considered the simplest, cheapest and most specific methods. ${ }^{2}$ Few studies have detected $\mathrm{H}$. pylori in gallstones but that cannot establish its association with cholecystitis. Some of the studies conducted in
Germany ${ }^{19}$, Brazil $^{20}$ and Iran $^{21}$ statistically show no significant association between $\mathrm{H}$ pylori and cholecystitis, but these studies were performed more than ten years back.

Symptoms of acid peptic disease and cholecystitis are related and confusingly similar most of the time. In this cross-sectional study, we aimed to identify the association of $\mathrm{H}$. pylori with cholecystitis ending up in cholecystectomy. If there is a significant evidence showing this relationship, this condition can be treated more conservatively. With the discovery of proton-pump inhibitors (PPIs) and triple therapy for $\mathrm{H}$ pylori infection, many gastric surgeries like Billroth I and II have become almost obsolete. Therefore, in the present study we looked for the presence of this microorganism in cholecystitis patients and its association with the morphological changes seen in gall bladders.

\section{Material and Methods}

This cross-sectional study was conducted by the Departments of Surgery and Pathology of Akbar Niazi Teaching Hospital (ANTH) Bara Kahu, Islamabad. Ethical approval was taken from Institutional Review Board of Islamabad Medical and Dental College. Sample collection was done using non probability convenience sampling. After taking informed consent, all patients with acute and chronic cholecystitis admitted in ANTH between the ages of 18 and 80 years from January 2017 till March 2019, who underwent cholecystectomy, were included in the study. Patients with Gall bladder tumors, hemolytic disease, patients who took triple regime antibiotic therapy for $\mathrm{H}$. pylori eradication for gastritis were excluded from the study.

Data was collected from a total of 100 patients by using HIMS (hospital information management system). It included patient's demographics i.e. age, gender, weight, residence and clinical data including; presenting complains, associated gastritis, comorbidity like diabetes, Total leukocyte court (TLC), Liver function tests (LFTs). Ultrasonographic findings of presence or absence of gall stones, gall bladder wall inflammation (edematous or wall thickness) and presence of pericholecystic fluid were also noted. 
Gall bladder specimens were sent to Pathology department, ANTH after surgery and specimens were analyzed for the presence of $\mathrm{H}$ pylori bacteria using $\mathrm{H} \& \mathrm{E}$ and Giemsa staining22. Signs of inflammation, hyperplasia, metaplasia, mucosal atrophy or erosion, lymphoid infiltration, fibrosis, cholesterolosis or any other morphological changes were noted. Result of categorical variables were presented as frequency and percentages. Continuous variables were expressed as mean and standard deviation. Association of H.pylori with cholecystitis, morphological changes and other variables was checked by $C h i$ Square test. $P \leq 0.05$ was considered statistically significant. Patients identity was not disclosed.

\section{Results}

A total of 100 patients underwent cholecystectomy. According to age, most of the patients $(n=52)$ were in 41 60 years' age group, followed by $20-40$ years $(n=38)$, and $61-80$ years age group $(n=10)$. Female predominance was observed with $88 \%$ females $(n=88)$ and $12 \%$ males $(n=12)$. All the patients had symptoms of upper abdominal pain and dyspepsia. Chronic cholecystitis was the most common presenting feature ( $91 \%$ ) followed by gall stones $(75 \%)$ and a few cases of acute cholecystitis (9\%). Other histological findings were Hyperplasia (10\%), Metaplasia (15\%), Fibrosis (79\%), Cholesterolosis (19\%) and Ulcerations (36\%). Histological appearance of Cholesterolosis is shown in Figure 1. H. pylori was seen in mucosa of gall bladders of 17 patients (17\%) (Figure 2).

Among those patients, male/female ratio was 1:7.5. Most of the patients were in the 41-60 years' age group. Chronic cholecystitis was present in all cases followed by gall stones. Fibrosis was the most common histological feature. Association of H-Pylori with gender, cholecystitis, gall stones, histological features and age distribution was non-significant (Table I).

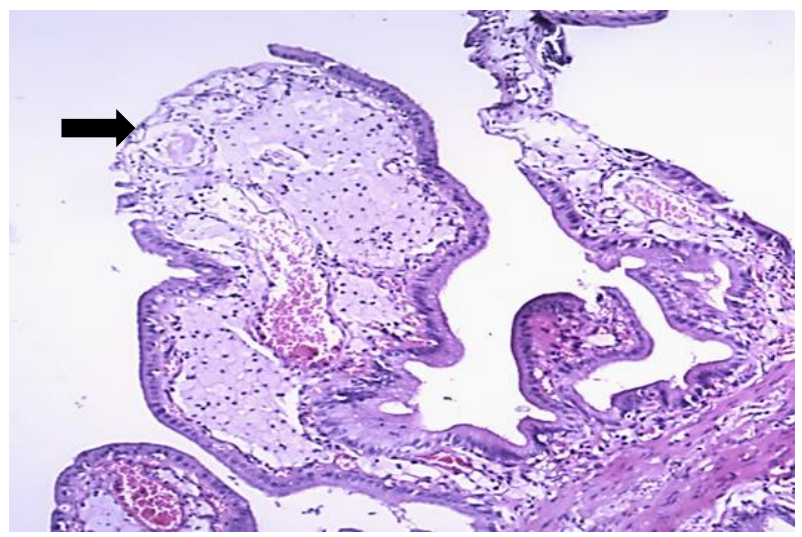

Figure 1: Section showing cholesterolosis (Lipid laden histiocytes) in lamina propria of gallbladder (H\&E X 100)

\begin{tabular}{|c|c|c|c|c|}
\hline & Features & $\begin{array}{c}\text { H pylori +ve } \\
\text { n (\%) }\end{array}$ & $\begin{array}{c}\text { H pylori-ve } \\
\text { n (\%) }\end{array}$ & $P$-value \\
\hline & \multicolumn{3}{|l|}{ Gender } & \multirow{3}{*}{0.97} \\
\hline 1 & Males & $2(11.7)$ & $10(83)$ & \\
\hline \multirow[t]{2}{*}{2} & Females & $15(88)$ & $73(82)$ & \\
\hline & \multicolumn{3}{|l|}{ Diagnosis } & \multirow{3}{*}{0.56} \\
\hline 1 & $\begin{array}{l}\text { Chronic } \\
\text { cholecystitis }\end{array}$ & $17(100)$ & $83(91)$ & \\
\hline \multirow[t]{2}{*}{2} & $\begin{array}{l}\text { Acute } \\
\text { cholecystitis }\end{array}$ & $0(0)$ & $9(100)$ & \\
\hline & \multicolumn{3}{|c|}{ Presence of Gallstones } & \\
\hline 1 & Gall stones & $13(76.4)$ & $62(82)$ & \multirow[t]{2}{*}{0.87} \\
\hline 2 & No gallstones & $4(23.5)$ & $21(84)$ & \\
\hline & \multicolumn{3}{|c|}{ Histological Features } & \multirow{6}{*}{0.59} \\
\hline 1 & Hyperplasia & $2(11.7)$ & $8(80)$ & \\
\hline 2 & Metaplasia & $3(17.6)$ & $12(80)$ & \\
\hline 3 & Fibrosis & 16(94.1) & $63(79.7)$ & \\
\hline 4 & Cholesterolosis & $4(23.5)$ & $15(98.9)$ & \\
\hline \multirow[t]{2}{*}{5} & $\begin{array}{l}\text { Erosions/ } \\
\text { Ulcerations }\end{array}$ & $3(17.6)$ & $33(91.6)$ & \\
\hline & Age Distributior & years) & & \multirow[b]{2}{*}{0.59} \\
\hline $\begin{array}{l}1 \\
2 \\
3\end{array}$ & $\begin{array}{l}20-40 \\
41-60 \\
61-80\end{array}$ & $\begin{array}{c}6(35.3) \\
11(64.7) \\
0(0)\end{array}$ & $\begin{array}{c}32(84.2) \\
41(78.8) \\
10(100)\end{array}$ & \\
\hline
\end{tabular}




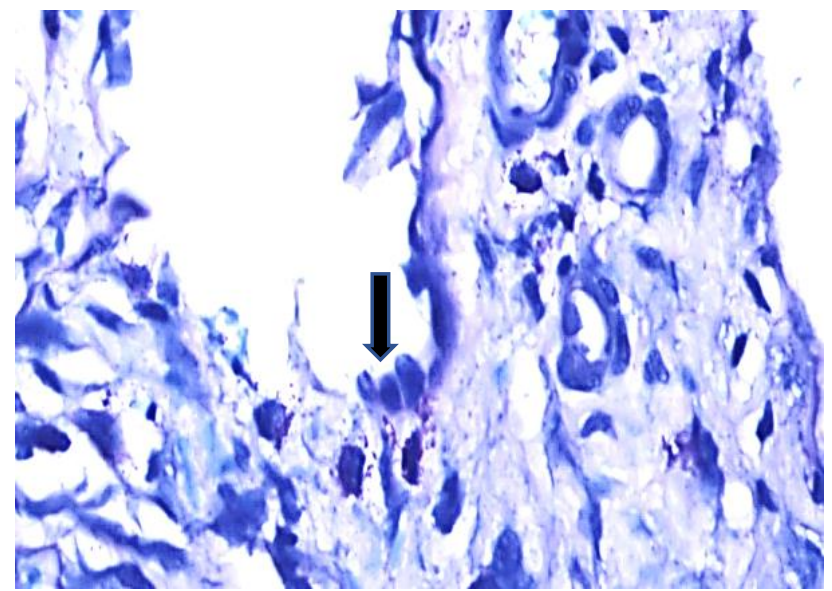

Figure 2: Histological section from gallbladder showing $\mathbf{H}$. pylori in the mucosa (Giemsa stain X 400).

\section{Discussion}

$\mathrm{H}$ pylori has been mostly associated with gastritis but its presence in other parts of gastrointestinal system has not been studied much. It was first detected in gall bladder by Kawaguchi in 1996, which opened the door to further research. ${ }^{12}$ The epithelial cells of human gallbladder can be damaged by $\mathrm{H}$. pylori leading to Cholecystitis. A metaanalysis of previous researches show association between gallbladder diseases and Helicobacter infection. ${ }^{3}$ It is also believed that chronic inflammation is an underlying cause of development and progression to cancers. Previous research has also shown that Helicobacters release metabolites and several toxins that are carcinogenic. ${ }^{23}$

So far, no definite association has been established between $\mathrm{H}$. pylori infection and cholecystitis. Also, there is no evidence of the exact pathway by which $H$. pylori bacteria reaches the hepatobiliary system. ${ }^{4}$

Risk factor such as age and gender play an important role in formation of gall stones but their role in chronic cholecystitis is still not clear. According to a study by Bohr et al, all female patients above 65 years of age had an association with gallstone formation. Another study by Bulajic, et al showed association of $\mathrm{H}$. pylori infection in bile with age but no association was seen with gender. In that study, more frequency of $\mathrm{H}$. pylori infection was present in patients above 70 years of age. ${ }^{4}$

Our study showed presence of $\mathrm{H}$. pylori in $17 \%$ of the gall bladder specimens with majority being females (88\%) with gallstones $(76.4 \%)$ and all of them having chronic cholecystitis. The most commonly involved age group was 41-60 years (64.7\%). Two studies conducted in Pakistan (Abro et $\mathrm{al}^{3}$ and Yakoob et $\mathrm{al}^{13}$ ) reported presence of $\mathrm{H}$. pylori in $55 \%$ and $25 \%$ patients respectively which is much higher than our patients (17\%).

All the patients in our study had symptoms of upper abdominal pain and dyspepsia and no difference was found in both the groups. In all $\mathrm{H}$ pylori positive cases, chronic cholecystitis was present (100\%), although a significant percentage of $\mathrm{H}$ pylori negative cases $(91 \%)$ also showed chronic inflammation.

Some of the studies have also shown an association of $\mathrm{H}$ pylori infection in gall bladders with gall bladder cancer. In a study by Bulajic et al, H. pylori was found 9.9 times more frequently in cases of gallbladder carcinoma when compared with normal controls and it was found 3.5 times more frequently in cases with gallstones. ${ }^{24}$ In another study, presence of Helicobacter pylori and Helicobacter bilis was confirmed in bile as well as gallbladder of patients having gallbladder carcinoma and chronic cholecystitis. It was observed that $\mathrm{H}$. pylori was present in more than $75 \%$ of patients with gallbladder cancer and it was present in more than $50 \%$ of patients having chronic cholecystitis. ${ }^{25}$ In our study, we did not find any such evidence but metaplasia was noted in $17.6 \%$ of the patients with $\mathrm{H}$ pylori infection and in $88 \%$ patients without $\mathrm{H}$ pylori infection. In a study by Hassan et al, metaplasia was found in $28 \%$ of the patients with $\mathrm{H}$ pylori infection and only $4 \%$ in patients without $H$ pylori infection. Therefore, in their study there was a statistically significant difference between the two groups $(P=0.049)$ regarding mucosal metaplasia. ${ }^{16}$

Regarding association of $\mathrm{H}$. pylori infection with gall stones, it was more common in $\mathrm{H}$. pylori negative cases $(82 \%)$ as compared to $\mathrm{H}$ pylori positive cases $(76 \%)$. The results were similar to that of another study in which the prevalence of gallstones in $\mathrm{H}$ pylori positive cases was lower than in the $\mathrm{H}$ pylori-negative cases (odds ratio, $0.653)^{11}$

In our study, fibrosis was present in most of the $\mathrm{H}$ pylori positive cases $(94 \%)$ whereas it was less $(79 \%)$ in non- 
infected patients proving its association with chronic cholecystitis. In another study, $36 \%$ cases of $\mathrm{H}$ pylori positive group had fibrosis but the same frequency was also seen in $\mathrm{H}$ pylori negative group and therefore no statistically significant difference was noted regarding fibrosis between both the groups ${ }^{16}$

When analyzed statistically, comparison of patients with $\mathrm{H}$ pylori positive and $\mathrm{H}$ pylori negative was not found significant in any of the findings. In another study, regarding gender, mean age, type of inflammation and stone formation, no statistically significant difference was noted between the two groups of $\mathrm{H}$ pylori positive and negative cases. ${ }^{16}$ Similarly in another study, similar results were found. ${ }^{26}$

It is still not known how these bacteria find their way into the gall bladder, but most probable theory is that it travels from stomach to duodenum and through sphincter of Odi enters the biliary system and resides in gall bladder.

\section{Conclusion}

$\mathrm{H}$ pylori infection has been found in cases of chronic cholecystitis and cholelithiasis, its association with cholecystitis and other morphological changes could not be proved. Hence, it is uncertain whether $\mathrm{H}$ pylori eradication in patients with gastritis can prevent cholecystitis or gall stones formation. Further studies are required with higher number of patients and different histological methods to prove this association.

\section{References}

1. Tazuma S. Gallstone disease: epidemiology, pathogenesis, and classification of biliary stones (common bile duct and intrahepatic). Best Pract Res Clin Gastroenterol. 2006; 20(6): 1075-83. Doi: 10.1016/j.bpg.2006.05.009

2. Channa NA, Khand FD, Bhanger MI, Leghari MH. Surgical incidence of Cholelithiasis in Hyderabad and adjoining areas (Pakistan). Pak J Med Sci. 2004; 20: 13-7.

3. Abro AH, Haider IZ, Ahmad S. Helicobacter pylori infection in patients with calcular cholecystitis: a hospital-based study. J Ayub Med Coll Abbottabad. 2011; 23(1): 30-3. PMID: 22830140
4. Cen L, Pan J, Zhou B, Yu C, Li Y, Chen W, Shen Z. Helicobacter Pylori infection of the gallbladder and the risk of chronic cholecystitis and cholelithiasis: A systematic review and meta-analysis. Helicobacter. 2018; 23(1): e12457. Doi: 10.1111/hel.12457

5. Fatemi SM, Doosti A, Shokri D, Ghorbani-Dalini S, Molazadeh M, Tavakoli $\mathrm{H}$ et al. Is There a Correlation between Helicobacter Pylori and Enterohepatic Helicobacter Species and Gallstone Cholecystitis? Middle East J Dig Dis. 2018; 10:24-30. Doi: 10.15171/mejdd.2017.86

6. Getachew A. Epidemiology of gallstone disease in Gondar University Hospital, as seen in the department of radiology. Ethiopia J Health Dev. 2016; 22(2). Doi: 10.4314/ejhd.v22i2.10074

7. Gunasekaran P, Vinson I. Helicobacter pylori colonization of gallbladder in patients with symptomatic cholelithiasis. Int Surg J. 2017; 4: 21946. Doi: 10.18203/2349-2902.isj20172765

8. Javaherzadeh M, Shekarchizadeh A, Sabet B, Mousavi-Almaleki SA, Mirafsharieh A. Simultaneous Helicobacter Pylori Infection in Gastric Mucosa and Gallbladder Mucosa in Patients with Cholecystitis; Is There Any Relationship? AJS. 2016; 3(1-2): 12-4.

9. Kheirmand F, Valadi F, Dolatshahi K. The presence of Helicobacter pylori in gallbladder mucosa of patients with chronic cholecystitis. Feyz. 2016; 20 (5): 454-60.

10. Athavale VS, Khandalkar SN, Bhide PC, Shetty I, Lad A. A study of association of $\mathrm{H}$. pylori infection and cholelithiasis. ISJ. 2018; 5(2): 701-4. Doi: 10.18203/2349-2902.isj20180377

11. Xu MY, Ma JH, Yuan BS, Yin J, Liu L, Lu QB. Association between Helicobacter pylori infection and gallbladder diseases: A retrospective study. J Gastroenterol Hepatol. 2018; 33(6): 1207-12. Doi: 10.1371/journal.pone. 0221076

12. Kawaguchi M, Saito $T$, Ohno H, Midorikawa S, Sanji $T$, Handa $Y$ et al. Bacteria closely resembling Helicobacter pylori detected immunohistologically and genetically in resected gallbladder mucosa. J Gastroenterol. 1996; 31(2): 294-8. Doi: 10.3748/wjg.v13.i10.1608

13. Yakoob J, Khan MR, Abbas Z, Jafri W, Azmi R, Ahmad $Z$ et al. Helicobacter pylori: association with gall bladder disorders in Pakistan. $\mathrm{Br} \mathrm{J}$ Biomed Sci. 2011;68(2):59-64. PMID: 21706915

14. Guraya SY, Ahmad AA, El-Ageery SM, Hemeg HA, Ozbak HA, Yousef $K$ et al. The correlation of Helicobacter Pylori with the development of 
cholelithiasis and cholecystitis: the results of a prospective clinical study in Saudi Arabia. Eur Rev Med Pharmacol Sci. 2015; 19(20): 3873-80. PMID: 26531273

15. Kountouras J, Tsiaousi E, Trigonis S, Zavos C, Kouklakis G. Helicobacter pylori infection in a Greek cohort with biliary disease. Br J Biomed Sci. 2014; 71(4):178-9. PMID: 25562997

16. Hassan EH, Gerges SS, El-Atrebi KA, El-Bassyouni $H T$. The role of $H$. pylori infection in gall bladder cancer: clinicopathological study. Tumour Biol. 2015;36(9):7093-8. Doi: 10.1007/s13277-015-3444-9.

17. Lee JY, Kim N. Diagnosis of Helicobacter pylori by invasive test: histology. Ann Transl Med. 2015; 3(1): 10. Doi: 10.3978/j.issn.2305-5839.2014.11.03.

18. Patnayak R, Reddy V, Jena A, Gavini S, Thota A, Nandyala $R$ et al. Helicobacter pylori in Cholecystectomy Specimens-Morphological and Immunohistochemical Assessment. Journal of clinical and diagnostic research: JCDR. 2016; 10(5):EC01. Doi: 10.7860/JCDR/2016/14802.7716

19. Takahashi Y, Yamamichi N, Shimamoto T, Mochizuki S, Fujishiro M, Takeuchi C, et al. Helicobacter pylori infection is positively associated with gallstones: a large-scale cross-sectional study in Japan. J Gastroenterol. 2014; 49(5): 882-9. Doi: 10.1007/s00535-013-0832-z

20. Bohr UR, Kuester D, Meyer F, Wex T, Stillert M, Csepregi $A$ et al. Low prevalence of Helicobacteraceae in gall-stone disease and gallbladder carcinoma in the German population. Clinical microbiology and infection. 2007; 13(5): 525-31. Doi: 10.1111/j.1469-0691.2007.01690.x
21. Sherafat SJ, Tajeddin E, Majidi MR, Vaziri F, Alebouyen $\mathrm{M}$, Alizade $\mathrm{AH}$. Lack of association between Helicobacter pylori infection and biliary tract diseases. PJM. 2012; 61(4): 319-22. PMID: 23484417

22. Silva CP, Pereira-Lima JC, Oliveira AG, Guerra JB, Marques DL, Sarmanho $L$ et al. Association of the presence of Helicobacter in gallbladder tissue with cholelithiasis and cholecystitis. Journal of clinical microbiology. 2003; 41(12): 5615-8. Doi: 10.1128/jcm.41.12.5615-5618.2003

23. Jergens $A E$, Wilson-Welder JH, Dorn A, Henderson A, Liu Z, Evans RB, et al. Helicobacter bilis triggers persistent immune reactivity to antigens derived from the commensal bacteria in gnotobiotic $\mathrm{C} 3 \mathrm{H} / \mathrm{HeN}$ mice. Gut. 2007; 56: 934-40. Doi: 10.1136/gut.2006.099242

24. Bulajic $M$, Maisonneuve $P$, Schneider-Brachert $W$, Müller P, Reischl U, Stimec B et al. Helicobacter pylori and the risk of benign and malignant biliary tract disease. Cancer: 2002; 95(9): 1946-53. Doi: 10.1002/cncr.10893

25. Murphy G, Michel A, Taylor PR, Albanes D, Weinstein SJ, Virtamo J, et al. Association of seropositivity to Helicobacter species and biliary tract cancer in the ATBC study. Hepatology. 2014; 60(6): 1963-71. Doi: 10.1002/hep. 27193

26. Motie M, Rezapanah A, Abbasi H, Memar B, Arianpoor A. The Relationship Between Cholecystitis and Presence of Helicobacter pylori in the Gallbladder, Zahedan J Res Med Sci. 2017; 19(7): e9621. Doi: 10.5812/zjrms.9621. 